\title{
A Novel Approach for Transmission of 56 Gbit/s NRZ Signal in Access Network Using Spectrum Slicing Technique
}

Spolitis, S.; Vegas Olmos, Juan José; Bobrovs, V.; Ivanovs, G.; Tafur Monroy, Idelfonso

Published in:

ACP/IPOC 2013

Publication date:

2013

Document Version

Publisher's PDF, also known as Version of record

Link back to DTU Orbit

Citation (APA):

Spolitis, S., Vegas Olmos, J. J., Bobrovs, V., Ivanovs, G., \& Tafur Monroy, I. (2013). A Novel Approach for

Transmission of $56 \mathrm{Gbit} / \mathrm{s}$ NRZ Signal in Access Network Using Spectrum Slicing Technique. In ACP/IPOC 2013 [AF4D.2] Optical Society of America.

\section{General rights}

Copyright and moral rights for the publications made accessible in the public portal are retained by the authors and/or other copyright owners and it is a condition of accessing publications that users recognise and abide by the legal requirements associated with these rights.

- Users may download and print one copy of any publication from the public portal for the purpose of private study or research.

- You may not further distribute the material or use it for any profit-making activity or commercial gain

- You may freely distribute the URL identifying the publication in the public portal 


\title{
A Novel Approach for Transmission of 56 Gbit/s NRZ Signal in Access Network Using Spectrum Slicing Technique
}

\author{
S. Spolitis ${ }^{1}$, J.J. Vegas Olmos ${ }^{2}$, V. Bobrovs ${ }^{1}$, G. Ivanovs ${ }^{1}$ and I. Tafur Monroy ${ }^{2}$ \\ Institute of Telecommunications, Riga Technical University, LV-1048, Riga, Latvia \\ ${ }^{2}$ DTU Fotonik, Dep. of Photonics Engineering, DTU, Ørsteds Plads 343, DK-2800 Kgs. Lyngby, Denmark \\ sandis.spolitis@rtu.lv
}

\begin{abstract}
We present the spectrum slicing and stitching concept for high-capacity low optics complexity optical access networks. Spectrum slicing and stitching of a 56 Gbit/s NRZ electrical signal is experimentally demonstrated for the first time.

OCIS codes: (060.2330) Fiber optics communications; (060.0060) Fiber optics and optical communications.
\end{abstract}

\section{Introduction}

Based on Cisco Visual Networking Index (VNI) forecast and methodology, global IP traffic has increased more than four times in the past 5 years, and will increase three times over the next 5 years. It will reach 1 zettabyte (ZB) per year or 83.8 exabytes (EB) per month in year 2015 and exceed 1.4 ZB per year or 120.6 EB per month threshold by the end of year 2017. Video-on-demand traffic will triple by 2016 . For these reasons there will be need for optical access networks which are capable to handle with large data amounts [1].

One of limiting factors in fiber optical access networks is the electronic bandwidth limitation, which leds to the fact that only a limited bandwidth can be transmitted and received. Therefore, the electronic part is commonly recognized as the bottleneck for optical access networks [2]. The future optical access network need to be effective it must be able to increase not only the spectral efficiency by employing complex modulation formats but also increase the utilization of the optical fiber capacity (dynamic changes of provided bandwidth by the customer's request). Spectrum-slicing technology is a potential solution of above mentioned problems since it allows transmission of large data amounts (wide waveforms) from the service provider (OLT - optical line terminal) to the end user (optical network unit - ONU) over optical distribution network (ODN) using already existing hardware (electrical components) of a passive optical network (PON) without requiring an upgrade on the bandwidth of the optical components [2].

\section{Spectrum slicing technique and principle}

Spectrum slicing technology allows significantly expand these limits without any additional complex requirements to electronics by slicing wide waveforms in lower speed slices and transmit each separate slice in parallel or one after another. In addition, spectrum slicing technology also gives an opportunity to improve optical system dispersion tolerance, and it is possible to double or even quadruple transmitted data amount by same waveform using more complex intensity modulation formats such as pulse amplitude modulation (M-PAM) or duobinary.

Recently, slicing and stitching of electrical signal in coherent high-speed optical networks using higher order modulation formats like binary phase-shift keying (BPSK), quadrature phase shift keying (QPSK) and eight phase shift keying (8PSK) has been demonstrated [3-5]. Our approach differs from these researches because we propose to use spectrum-slicing in simple intensity modulated direct-detection (IMDD) PON systems. Consequently, our paper reports on a feasible and simple solution for the possible implementation of spectrum slicing technology in fiber optical access networks significantly increasing the limits of existing electronics.

\section{Experimental setup and results}

Fig. 1 shows a high level visualization of the access system setup implemented in the experiment. As it can be observed, a $56 \mathrm{Gbit} / \mathrm{s}$ electrical signal is sliced into six lower speed spectral slices. Afterwards using off-line digital signal processing (DSP) these slices are stitched together to form a reconstructed continuous $56 \mathrm{GHz}$ NRZ electrical signal waveform. To generate the original real data, two uncorrelated $28 \mathrm{Gbit} / \mathrm{s}$ channels of a pulse pattern generator (PPG) were multiplexed to form a $56 \mathrm{Gbit} / \mathrm{s}$ NRZ signal. The pseudo random binary sequence (PRBS) had a pattern length of $2^{15}-1$. A $63 \mathrm{GHz}$ digital sampling oscilloscope (DSO) with a $160 \mathrm{GSa} / \mathrm{s}$ sample rate was used to store the received waveform for offline processing, see Fig. 1. At first, the captured electrical signal at the OLT was sliced in six slices using spectral slice filters with different central frequencies, and equal bandwidths of $9.34 \mathrm{GHz}$ each. In this case, we chose to slice signal in six slices to fit within $10 \mathrm{Gbit} / \mathrm{s}$ electronic limits. After slicing process each 
separate electrical slice, except the first, are down-converted to the baseband. This process enables each slice to be modulated by regular access network elements (e.g. modulators - Mach-Zehnder (MZM) or electro-absorption (EAM) modulators). Afterwards each separate spectral slice can be placed on specified carrier wavelength and transmitted over ODN where a span of standard single mode optical fiber (SMF) is deployed.

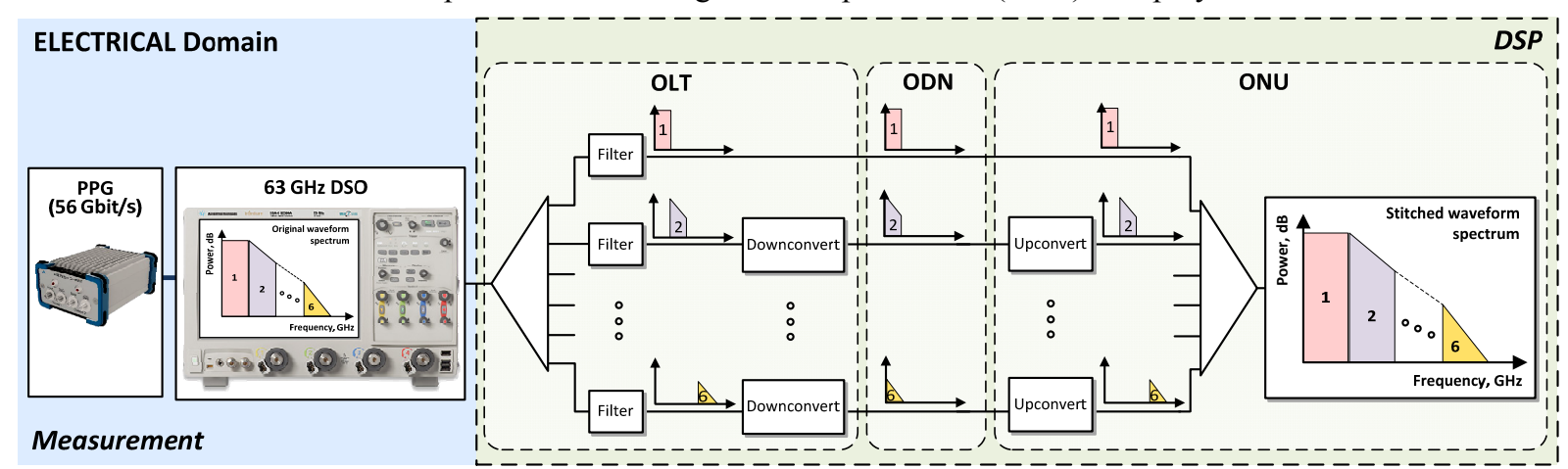

Fig.1. Experimental setup for parallel transmission of six spectral slices and waveform reconstruction using DSP

In receiver side or ONU, optical signals can be detected with photodiodes (PD) or avalanche photodiodes (APD) and converted to electrical signals. In ONU all six electrical signals (slices) are upconverted to their proper positions and combined into a contiguous spectrum containing measured waveform, see Fig. 1 (d).

Fig. 2 (a) and 2 (b) show the power spectral density (PSD) and eye diagram of back-to-back 56 Gbit/s NRZ electrical signal captured with the DSO. As it can be observed in Fig.2 (b), the quality of the input electrical NRZ signal is acceptable, eye diagram is open and there are no signal distortions.

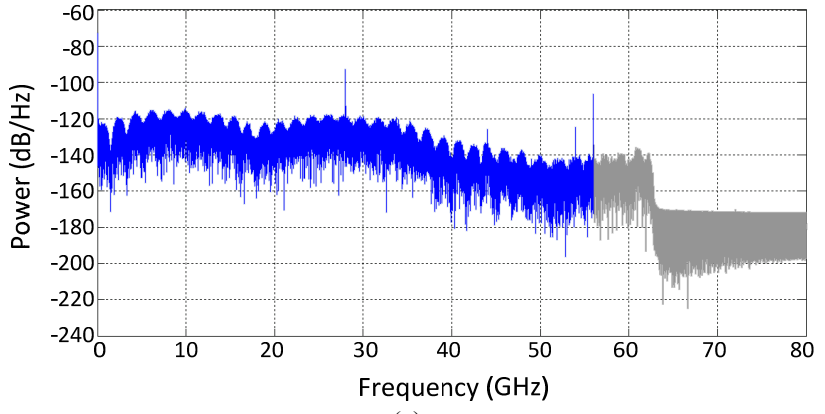

(a)

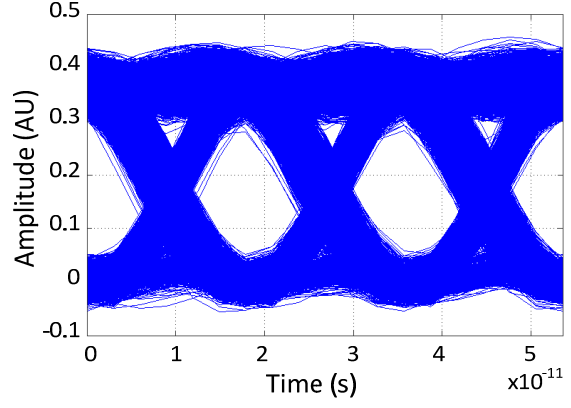

(b)

Fig. 2. (a) Power spectral density of captured $56 \mathrm{GHz}$ NRZ signal and (b) eye diagram of captured $56 \mathrm{Gbit} / \mathrm{s}$ NRZ signal

Figure 3 shows some of the $9.34 \mathrm{GHz}$ slices from the original $56 \mathrm{Gbit} / \mathrm{s}$ NRZ electrical signal and the slices once they are downconverted to baseband for transmission.
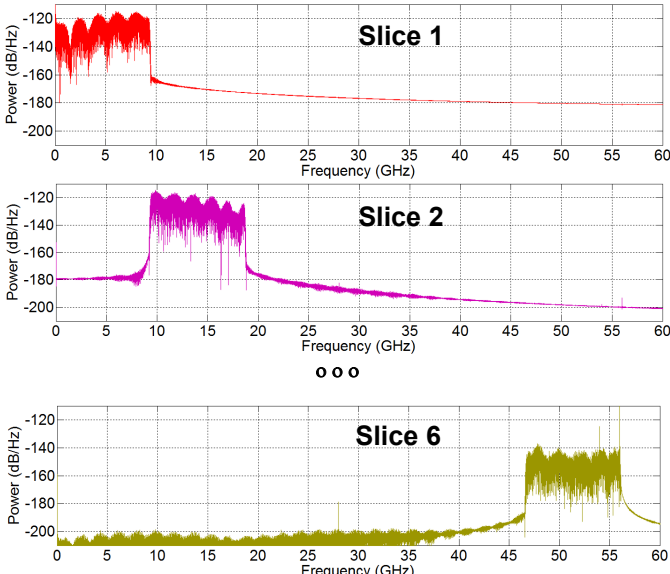

(a)
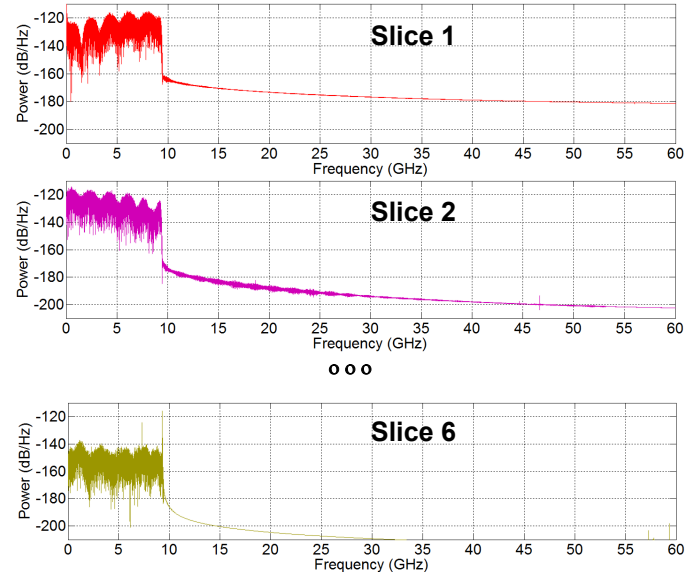

(b)

Fig. 3. Power spectral density of sliced electrical $56 \mathrm{Gbit} / \mathrm{s}$ NRZ signal (a) slices after slice filter (b) slices moved to baseband 
Finite impulse response filters (FIR) with linear phase characteristics and $9.34 \mathrm{GHz}$ bandwidth was used as slice filters. Due to high FIR filter order $(\mathrm{M}=2000)$, the overlapping region of slices was about $0.02 \mathrm{GHz}$ which is relatively small. There is acceptable minimal overlap of the adjacent spectral slices to avoid information loss due to spectral space between slices. After transmission of these slices they are restored to their proper positions and stitched together to form continuous waveform, see Fig. 4 (a). Eye diagram and power spectral density of restored waveform is represented in Fig. 4.

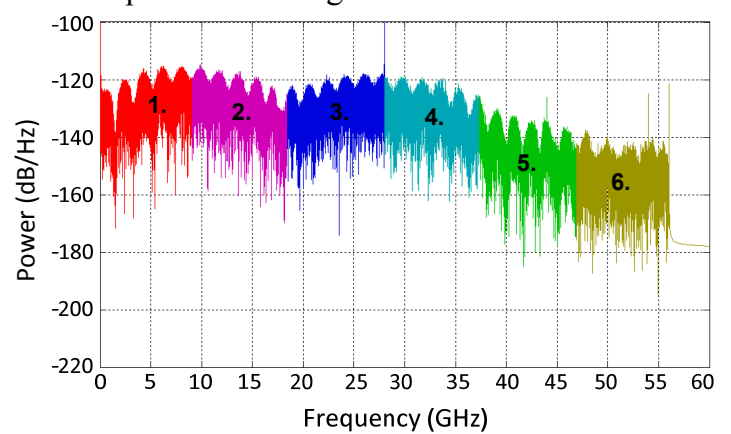

(a)

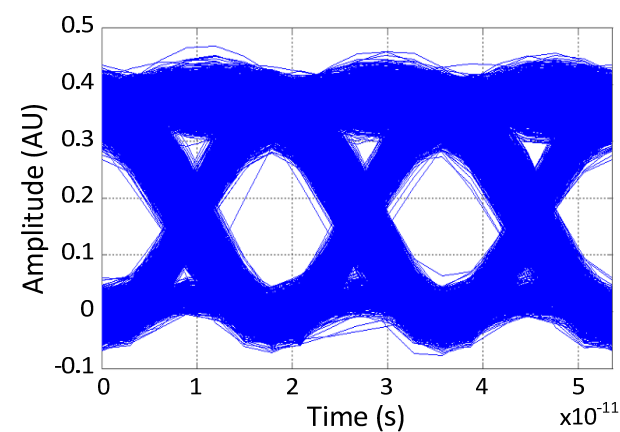

(b)

Fig. 4. (a) Power spectral density of restored $56 \mathrm{GHz}$ NRZ signal (b) eye diagram of restored 56 Gbit/s NRZ signal

Figure 4 shows power spectral density and eye diagram of restored 56 Gbit/s NRZ signal, which demonstrates that it can be sliced in six different slices and stitched back into initial continuous waveform. The eye diagram quality of the restored electrical $56 \mathrm{Gbit} / \mathrm{s}$ NRZ signal is acceptable and without any major signal distortions, see Fig. 4 (b).

\section{Conclusion}

A spectrum slicing and stitching of an electrical $56 \mathrm{Gbit} / \mathrm{s} \mathrm{NRZ} \mathrm{signal} \mathrm{is} \mathrm{demonstrated} \mathrm{for} \mathrm{the} \mathrm{first} \mathrm{time.} \mathrm{This}$ experimentally demonstrated concept for high-capacity low optics complexity optical access networks provides potentially effective way for transmission of high-speed (wide bandwidth) signals by using conventional electronics with much lower speed (narrow bandwidth). In our research, we showed a scenario of $56 \mathrm{GHz} \mathrm{NRZ}$ signal transmission in six parallel slices which can be realized using electronics with only $10 \mathrm{GHz}$ bandwidth. To the best of the authors' knowledge, this approach is new and has a large potential in non-coherent intensity modulated direct detection (IM-DD) fiber optical access networks which allows transmitting larger information amounts using already existing electronics and optical elements. For example, this approach may have a large potential in timedivision multiplexed PON networks where it could be possible to transmit and receive $100 \mathrm{Gbit} / \mathrm{s}$ waveforms using existing $10 \mathrm{GHz}$ electronics by slicing these $100 \mathrm{GHz}$ waveforms in 10 separate electrical slices and send each slice one after another in each particular timeslot. Alternatively, signals employing advanced modulation formats that increase the spectral efficiency (SE), can be decomposed in even smaller bandwidth slices, virtually reconfiguring the effective bandwidth of the receiver.

\section{Acknowledgements}

This work has been supported by the European Social Fund within the project «Support for the implementation of doctoral studies at Riga Technical University». J.J. Vegas Olmos acknowledges the Marie Curie program for partly funding this research through the FENDOI project.

\section{References}

[1] Cisco Inc., "Cisco visual networking index: Forecast and methodology, 2012-2017," (2013).

[2] D. J. Geisler, N. K. Fontaine, R. P. Scott, T. He, L. Paraschis, O. Gerstel, J. P. Heritage, and S. J. B. Yoo, "Bandwidth scalable, coherent transmitter based on parallel synthesis of multiple spectral slices" in OFC/NFOEC, paper OTuE3, (2011).

[3] D. J. Geisler, N. K. Fontaine, R. P. Scott, and S. J. B. Yoo, "Demonstration of a Flexible Bandwidth Optical Transmitter/Receiver System Scalable to Terahertz Bandwidths," IEEE Photonics Journal, vol.3, no.6, pp. 1013 - 1022, (2011).

[4] N. K. Fontaine, "Spectrally-sliced coherent receivers for THz bandwidth optical communications" in Proc. IEEEI, Invited paper, (2012).

[5] N. K. Fontaine, G. Raybon, B. Guan, A. L. Adamiecki, P. Winzer, R. Ryf, A. Konczykowska, F. Jorge, J. Dupuy, L. L. Buhl, S. Chandrasekhar, R. Delbue, P. Pupalaikis, and A. Sureka, "228-GHz Coherent Receiver using Digital Optical Bandwidth Interleaving and Reception of 214-GBd (856-Gb/s) PDM-QPSK" in ECOC, paper Th3A1, (2012). 